УДК 336.71

\title{
ИСТОРИЯ РАЗВИТИЯ И ИССЛЕДОВАНИЯ БАНКОВСКИХ СИСТЕМ В КИТАЕ
}

\section{Шэнь Бинбин}

аспирант

«Новосибирский государственный университет»

Аннотация: В финансовой системе Китая банки имеют доминирующее значение. Реформа и развитие банковской отрасли связаны с реформированием и развитием всей экономической системы. В любой стране банковская отрасль является основной частью финансовой системы. Если развивающаяся страна игнорирует промышленную структуру реальной экономики и характеристики финансового спроса и создаёт банковскую структуру, в которой доминируют крупные банки, то легко привести к отклонению банковской структуры от финансовых потребностей реальной экономики. В этом случае, даже если есть Политика финансового подавления, такая как контроль процентных ставок и государственное вмешательство, также трудно повысить эффективность банковской системы и полностью задействовать функцию финансовых услуг для реальной экономики. В статье рассматриваются особенности становления и развития банковской системы Китая на разных этапах развития.

Ключевые слова: банковская система, коммерческие банки, реформа, рыночная экономика.

\section{HISTORY OF DEVELOPMENT AND RESEARCH OF BANKING SYSTEMS IN CHINA}

\section{Shen Bingbing}

\begin{abstract}
In China's financial system, banks are dominant. Reform and development of the banking industry are associated with the reform and development of the entire economic system. In any country, the banking industry is the main part of the financial system. If a developing country ignores the industrial structure of the real economy and the characteristics of financial demand and
\end{abstract}


creates a banking structure dominated by large banks, it is easy to cause the banking structure to deviate from the financial needs of the real economy. In this case, even if there are no financial suppression policies such as interest rate controls and government intervention, it is also difficult to improve the efficiency of the banking system and fully utilize the financial services function for the real economy. The article examines the features of the formation and development of the Chinese banking system at different stages of development.

Key words: banking system, commercial banks, reform, market economy.

\section{Введение}

Китайская экономика развивалась в течение 30 лет реформ и развития. В то же время банковская отрасль также развивалась быстрыми темпами. В китайской банковской системе есть свои особенности. Во-первых, она находиться под сильным влиянием со стороны правительства. Оно заключается в стремлении использовать коммерческие банки для решения государственных проблем: финансирование перспективных с точки зрения китайского общества предприятий и проектов, в контроле за денежными и валютными операциями. Кроме этого, правительство использует банковскую систему для проведения экономических реформ, особенно в создании эффективного финансового рынка. Во-вторых, банковский сектор сильно сегментирован. В нем выделяются системные банки, которые, совместно с правительством реализуют финансирование крупных народнохозяйственных и международных проектов. Третья особенность - функционирование в процессе реформ. Это подразумевает определенное партнёрство банковской системы и государство. Оно реализуется через тщательные контроль за работой банков и вмешательство в тот момент, когда необходима помощь банкам или их участие.

\section{Происхождение банковской системы КНР}

Со времён династии Тан в Китае существовала концепция банка: с 847 по 858 год нашей эры «золотой банк» в Сучжоу [1, с. 70]. Термин «банк» впервые предложил Cai Xiang в 1057 г. В то время у банки выполняли мало функций. Первым специализированным кредитным учреждением в Китае был государственный банк, а позже появились частные банки [2, с. 9]. Раньше банк в Китае был кредитным учреждением, образованным в результате развития рынка и индустрии обмена денег. Северный и южный Китай называли серебряными домами, а бассейн реки Янцзы, включая Шанхай, 
назывался домом банка. Основанное в 1823 году [3, с.74], «денежные дома» (Rishengchang Piaohao) - первое частное финансовое учреждение в Китае, которое специализировалось на депозитах, кредитовании и обменных услугах. Существовала проблема локализации в развитии банков. Для того, чтобы обобщить историю современного китайского банковского дела, необходимо рассмотреть его теорию. Современная банковская теория Китая является результатом западных банковских теорий, импортированных и изначально укоренившихся в Китае. Ещё в 19 веке китайцы начали изучать западную экономику и западные финансовые теории. В то время китайцы переводили «bank» как «Yinhang». Он не только отражает разницу между банками и «денежными домами» (китайскими «Qianzhuang» и «Piaohao»), но и ясно показывает природу банков, отражая мудрость китайцев и их понимание западной экономики. Поэтому термин «банк» получил широкое распространение в Японии и Юго-Восточной Азии. Первым банком национального капитала в Китае был Китайский коммерческий банк, основанный 27 мая 1897 года. Ещё Commercial Bank был основан г-ном Sheng Xuanhuai. Это первый коммерческий банк в истории Китая с капиталом в 5 миллионов таэлей. Акционеры - феодальные бюрократы, компрадоры и капиталисты денежных домов. «Hubu Bank», основанный в 1904 году, представляет собой типичный управляемый государством банк, созданный для решения финансового кризиса феодального правительства, и является финансовым инструментом правительства Цин [4, с. 7]. В феврале 1908 года Банк Министерства народных хозяйств был переименован в «Банк династии Цин» [5, с.126]. Банк династии Цин выполнял необходимые национальные финансовые функции, но также были следы стандартизированной бизнесмодели современного банковского дела.

\section{История развития банковской системы КНР}

Банковская отрасль Китая вступила в стадию роста, но в этот период возникла проблема крупномасштабных банкротств банков Китая. 16 августа 1924 года Южное революционное правительство первоначально учредило центральный банк в Гуанчжоу [6, с. 158]. Банк был реорганизован в Центральный банк Гуандуна в феврале 1929 года, а затем реорганизован в Банк провинции Гуандун в январе 1932 года. После создания Нанкинского национального правительства 1 ноября 1928 года в Шанхае был создан ещё один центральный банк. После начала Первой мировой войны он переместился на запад в Нанкин, Ухань и Чунцин, а после войны вернулся в 
Шанхай. Ma Yanchu (1929) [7, с. 49] был первым, кто предложил новую политику центрального банка, например, в области переучёта. Это нашло отражение в книге «China Banking Theory». В 1933 году Wu Qixiang и другие китайские экономисты подчеркнули независимость центрального банка в системе «Банка Китая» [8, с. 109]. В 1937 году в «Новой денежно-кредитной политике Китая» $\mathrm{Yu}$ Jieqiong предложил контролировать соотношение активов и пассивов банков [9, с. 5]. В 1942 году Liu Zelin сделал в своей книге «Bank State-owned Theory» следующие выводы: банки должны принять «систему штаб-квартир и отделений» $[10$, с. 25$]$. Головной офис банка должен чётко формулировать планы и устанавливать основные принципы, а также согласованно работать с филиалом. Отказ от «денежных домов» (китайских «Qianzhuang» и «Piaohao») до появления современных банков — это далеко не просто изменение названия. Несмотря на то, что они занимались одной деятельностью, их организационные структуры, механизмы работы и концепции были совершенно разные, и исследователям банковской истории следует на это обратить внимание. Во-первых, весь бизнес банка основан на платежах и расчётах. Во-вторых, рост и падение банков связаны с действиями правительства. В-третьих, банковские дома в основном обслуживают коммерческий капитал. Долгосрочные ссуды выдаются на срок от трёх до шести месяцев. Краткосрочные ссуды рассчитываются на ежедневной основе. Срок ссуды короткий, что отражает особенности современной промышленной структуры Китая, то есть низкий удельный вес вторичной промышленности. В-четвёртых, надёжность банка основана на неограниченной ответственности акционеров и прямых взаимоотношениях между акционерами и менеджментом, таких как родство, география и личные связи. В-пятых, «денежные дома» являлись производными от платежей и расчётов, а также были основаны на них. Мощная функция клиринга является важной причиной, по которой «денежные дома» могли сосуществовать с банками в течение длительного времени. Первый финансируемый Китаем банк, «China Commercial Bank», был основан в 1897 году. С 1897 года до конца Первой мировой войны китайский банковский сектор завершил 200-летний процесс западных финансов.

\section{Исследование банковской системы КНР}

В Китае действует единая система центрального банка. Банковская система Китая состоит из центрального банка, регулирующих органов, саморегулируемых организаций и банковских финансовых учреждений. 
Народный банк Китая является центральным банком. Комиссия по регулированию банковской деятельности и страхования Китая, именуемая Комиссией по регулированию банковской деятельности и страхования Китая или Комиссией по регулированию банковской деятельности Китая, отвечает за надзор за банковскими финансовыми учреждениями и их коммерческой деятельностью по всей стране. Китайская банковская ассоциация - это национальная некоммерческая общественная организация, зарегистрированная в Министерстве по гражданским делам и саморегулируемая организация китайской банковской индустрии. Банковские финансовые учреждения Китая включают политические банки (Китайский банк развития, Экспортно-импортный банк Китая, Банк сельскохозяйственного развития Китая), крупные коммерческие банки (ICBC, Банк Китая, Сельскохозяйственный банк Китая, Строительный банк Китая, Банк коммуникаций), малые и средние банки Коммерческие банки, сельские финансовые учреждения, Почтовый сберегательный банк Китая и иностранные банки. Небанковские финансовые учреждения, регулируемые Комиссией по регулированию банковской деятельности Китая, включают компании по управлению финансовыми активами, трастовые компании, корпоративные финансовые компании группы, финансовые лизинговые компании, автомобильные финансовые компании и компании валютных брокеров.

(1) Первоначальное становление банковской индустрии (1948-1952 гг.). Социалистическая банковская система Китая была создана в конце 1940-х годов на основе бывшей советской системы. В 1949 году Китай официально передал Народному банку Китая функции национального банка. В период восстановления национальной экономики Народный банк Китая приступил к созданию национальной банковской системы Китая [11, с. 1].

(2) Период плановой экономики (1953-1978 гг.). В период «плановой экономики» китайская банковская система была «универсальной» системой управления, которая была совместима с плановой экономической системой. Филиалы Народного банка Китая на всех уровнях передавали поглощённые и хранимые средства в головной офис, а головной офис следовал общенациональному общему плану строительства. Цель требует разработки плана кредитования и выдачи показателей кредитоспособности и линий для подчинённых филиалов [12, с. 17].

(3) После реформы и открытости (с 1978 г. по настоящее время). 
Таблица 1

Этапы рыночной банковской реформы в Китае

\begin{tabular}{|l|l|l|}
\hline Период & Этап & Основные события \\
\hline $\begin{array}{l}1978- \\
1993 \text { гг. }\end{array}$ & $\begin{array}{l}\text { Переход } \\
\text { на специализацию. }\end{array}$ & $\begin{array}{l}\text { Банковскую систему возглавляет Народный банк } \\
\text { Китая и четыре крупных государственных } \\
\text { профессиональных банка стали основным } \\
\text { источником корпоративных средств. }\end{array}$ \\
\hline $\begin{array}{l}1994- \\
2003 \text { гг. }\end{array}$ & $\begin{array}{l}\text { Переход } \\
\text { к коммерциализации. }\end{array}$ & $\begin{array}{l}\text { В } 1999 \text { году были созданы четыре компании по } \\
\text { управлению финансовыми активами. }\end{array}$ \\
\hline $\begin{array}{l}2005- \\
2010\end{array}$ & $\begin{array}{l}\text { Эт. } \\
\text { к маркетингизации. }\end{array}$ & $\begin{array}{l}\text { Акции четырёх крупнейших государственных } \\
\text { коммерческих банков Китая торгуются на бирже. }\end{array}$ \\
\hline $\begin{array}{l}\text { после } \\
2010 \text { г. }\end{array}$ & $\begin{array}{l}\text { Новая } \\
\text { эра качественного } \\
\text { развития банковской } \\
\text { системы. }\end{array}$ & $\begin{array}{l}\text { В 2018 году Комиссия по регулированию } \\
\text { банковской деятельности Китая и Комиссия по } \\
\text { регулированию страхования Китая объединились в } \\
\text { Комиссию по регулированию банковской } \\
\text { деятельности и страхования Китая. }\end{array}$ \\
\hline
\end{tabular}

В 1978 году Китай начал внедрять рыночную экономику. После разрушения «универсальной» банковской системы новые финансовые организации продолжали создаваться в процессе внедрения новых моделей, а банковская отрасль продемонстрировала диверсифицированную тенденцию развития.

Первый этап (1978-1993 гг.): Переход на специализацию. В марте 1978 года Народный банк Китая стал независимым от Министерства финансов, и Китай первоначально создал систему центрального банка с китайскими особенностями. С 1979 по 1984 год последовательно возобновляли свою деятельность Сельскохозяйственный банк Китая, Банк Китая, Народный строительный банк Китая и Промышленно-коммерческий банк Китая. После восстановления и создания государственных профессиональных банков банковский бизнес и сферы деятельности значительно расширились: практически весь оборотный капитал единолично управляется банками, а четыре крупных государственных профессиональных банка стали основным источником корпоративных средств.

Второй этап (1994-2003 гг.): Переход к коммерциализации. В 1994 году (для выделения политических предприятий) один за другим были созданы три основных политических банка: Китайский банк развития, Экспортноимпортный банк Китая и Китайский банк сельскохозяйственного развития. В 1999 году с целью продажи неработающих активов четырёх крупных банков, 
одна за другой были созданы четыре компании по управлению финансовыми активами: China Huarong Asset Management Corporation (CHAMC), China Great Wall Asset Management Corporation (GWAMC), China Cinda Asset Management Corporation (CINDAMC) и China Oriental Asset Management Corporation (СОАМС). Реформа банковской отрасли в период перехода к коммерциализации заключается в следующем: во-первых, это усиление построения системы надзора и управления и создание сильной системы макроконтроля центрального банка. В мае 2000 года была создана Китайская банковская ассоциация. В апреле 2003 года для усиления финансового надзора была создана Комиссия по регулированию банковской деятельности Китая. Во-вторых, это разделение финансирования политики и коммерческого финансирования, формирование системы финансовой организации с государственными банками в качестве основного органа и политическими финансовыми учреждениями, сосуществующими с несколькими финансовыми учреждениями. В-третьих, это укрепление правовой системы и принятие соответствующих законов («Закон о Народном банке Китая» и «Закон о коммерческих банках»), для обеспечения правовой защиты коммерческих банков и их независимости, куда входит и ответственность банков за собственные риски, прибыль и потери.

Третий этап (2005-2010 гг.): Этап перехода к маркетингизации. В 2004 году Государственный совет Китая инициировал реформу акционерного капитала государственных банков и способствовал созданию современной системы финансовых предприятий. В ходе реформы использовался последовательный рыночный подход. Четыре крупных государственных коммерческих банка провели реформу акционерного капитала и постепенно стали современными финансовыми предприятиями. По состоянию на 2010 год четыре крупнейших государственных коммерческих банка Китая успешно прошли листинг на Шанхайской фондовой бирже и Гонконгской фондовой бирже, и реформа акционерного капитала государственных коммерческих банков была завершена [13, с. 1].

Четвёртый этап (с 2010 г.): вступление в новую эру качественного развития. В новую эпоху экономический рост переходит на более высокий уровень развития. Финансовый сектор должен был повысить свою способность обслуживать реальную экономику, увеличить долю прямого финансирования, улучшить систему регулирования и предотвратить системные финансовые риски [14, с. 55]. В 2018 году Комиссия по 
регулированию банковской деятельности Китая и Комиссия по регулированию страхования Китая объединились в Комиссию по регулированию банковской деятельности и страхования Китая. Из-за жёсткой регуляторной политики в финансовом секторе Китая новые предприятия многих банков развивались медленно, что увеличивало давление на качество банковских активов и создание резервов, что, в свою очередь, влияло на прибыльность (табл.2).

Таблица 2

Прибыль банковских финансовых учреждений после уплаты налогов (единица: 100 млн юаней)

\begin{tabular}{lllllll}
\hline & 2015 & 2016 & 2017 & 2018 & 2019 & 2020 \\
\hline Банковские финансовые учреждения & 19738 & 20732 & 22008 & 22848 & 23962 & 22626 \\
$\begin{array}{l}\text { Политические банки и Китайский банк } \\
\text { развития }\end{array}$ & 1162 & 1254 & 112 & 1321 & 1368 & 1169 \\
Крупные коммерческие банки & 8925 & 8790 & 9178 & 9573 & 10606 & 10925 \\
Акционерные коммерческие банки & 3373 & 3534 & 3684 & 3881 & 4233 & 4107 \\
Городские коммерческие банки & 1994 & 2245 & 2474 & 2461 & 2509 & 2146 \\
Сельские коммерческие банки & 1487 & 1785 & 1975 & 2094 & 2287 & 1953 \\
Сельские кооперативные банки & 82 & 38 & 24 & 14 & 10 & 8 \\
Сельские кредитные кооперативы & 664 & 519 & 489 & 400 & 294 & 174 \\
Небанковские финансовые учреждения & 1437 & 1555 & 2315 & 2176 & 2257 & 1804 \\
Иностранные банки & 153 & 128 & 147 & 248 & 216 & 170 \\
Новые сельские финансовые учреждения & 115 & 108 & 115 & 100 & 101 & 77 \\
\hline
\end{tabular}

Источник:https://www.cbirc.gov.cn/cn/view/pages/ItemDetail.html?docId=97 0583\&itemId $=954 \&$ generaltype $=0$

После 2018 года, создавая современную финансовую систему, Китай ввёл ряд новых реформ и мер открытости, таких как эффективное предотвращение финансовых рисков, корректировка и улучшение финансовой нормативной базы, стандартизация бизнес-механизмов управления активами, внедрение комплексных и высоких уровней открытости банковского сектора, углубление структурных реформ в сфере финансового предложения и другие. Согласно публичным данным Китайской комиссии по регулированию банковской и страховой деятельности (CBIRC), темп роста чистой прибыли китайских коммерческих банков с 2011 по 2019 год составил 36.3\%, 19\%, 14.5\%, $12.1 \%, 10.5 \%, 4 \%, 6 \%, 4.7 \%, 8.9 \%$, видно, что прибыльности китайских коммерческих банков за последние годы упали. (рис. 1). 


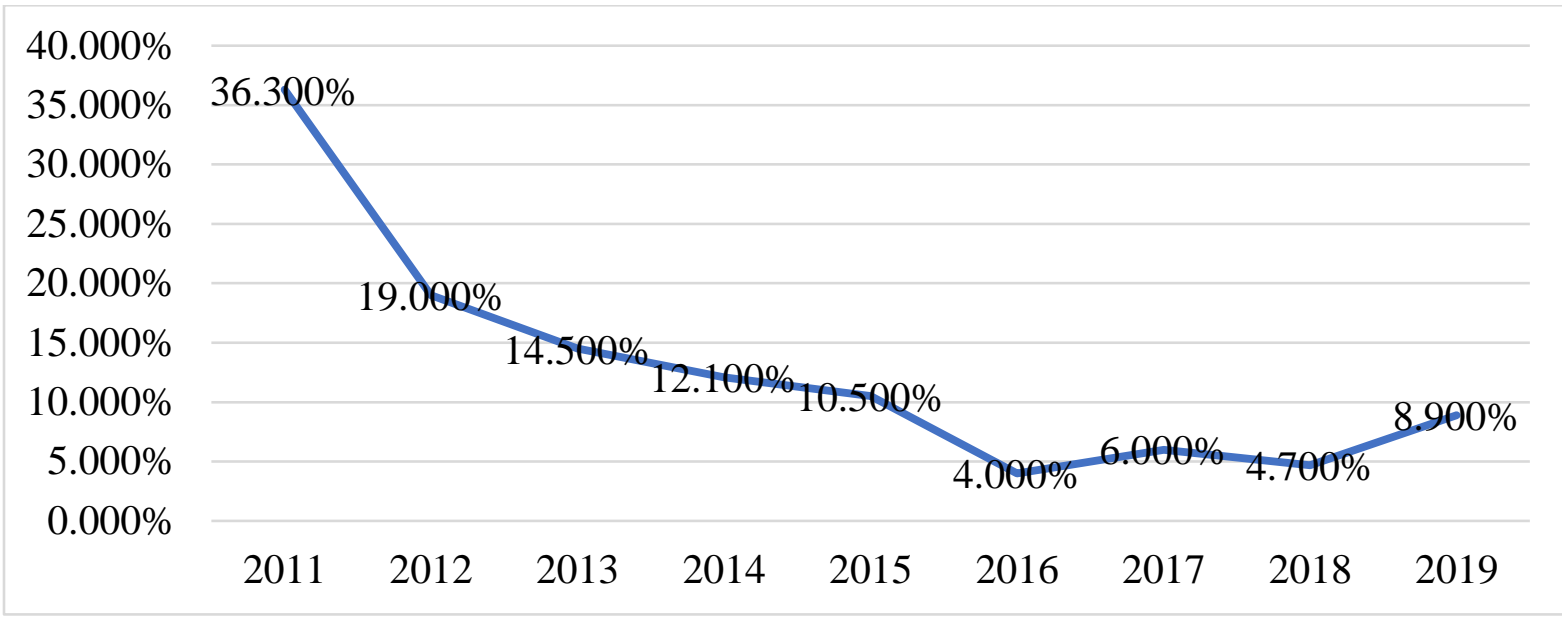

\section{Рис.1. Темпы роста чистой прибыли китайских коммерческих банков с 2011 по 2019 гг.}

Источник: Составлено автором

Снижение прибыльности банков в основном связано как с внутренними, так и с внешними факторами. Среди них внешние факторы, такие как низкие темпы роста и низкие процентные ставки, сильные регулятивные эффекты и конкуренция со стороны небанковских организаций, снизили прибыльность банков. Внутренние структурные факторы, такие как недостаточная операционная эффективность и высокая стоимость самих банков, замедлили рост банковской прибыли.

\section{Заключение}

Банковская система Китая движется в направлении постепенного улучшения и повышения устойчивости, но в этом процессе банковская система Китая также обнажила множество проблем: государственным коммерческим банкам не хватает внутренней мотивации, конкуренции и осведомлённости о рисках. В течение долгого времени китайские банки создавали огромное чувство доверия в сердцах широкой публики, но это чувство доверия проистекает из доверия людей к правительству и является результатом долгосрочного государственного вмешательства, a не значительных результатов в банковских операциях. Кроме того, правительство по-прежнему различными замаскированными способами вмешивается в хозяйственную деятельность банков и государственных предприятий.

Ввиду текущих проблем в банковской системе Китая, в сочетании с национальными условиями и экономическим развитием Китая, стоит 
рассмотреть следующие аспекты. Во-первых, провести необходимые реформы для устранения банковских рисков и поддержки долгосрочного устойчивого роста. Во-вторых, установите постоянные и долгосрочные отношения сотрудничества между банками и предприятиями, чтобы банки и предприятия могли развиваться совместно. Это может снизить стоимость финансирования предприятия, поддержать долгосрочную и непрерывность экономики предприятия и в то же время сохранить стабильный основной источник дохода по обязательствам банка. В-третьих, для китайской банковской отрасли, увеличение доли непроцентных доходов является основной задачей реформы операционной структуры каждого банка КНР, а также необходимой мерой для повышения конкурентоспособности на рынке.

\section{Список литературы}

1. Ван Нана, Исследование исторической эволюции бизнеса кредитных карт. // Исследование производительности, 2012 (03): 70-73.

2. Сыма Юньцзе. Культурное и философское мышление крупных банков - также о теории валютной функции. // Финансы Экспорт, 2016 (01): 9-10.

3. Цай Яньпин. Философское мышление о внутреннем контроле коммерческих банков. // Сборник западных исследований, 2009 (06): 74-75.

4. Ма Вэйхонг. Философское предположение об ограниченной рациональности и его применение при принятии решений по банковским кредитам, Тяньцзиньский университет, 2009: 7-20.

5. Ли Хуамин. Философское мышление о выборе пути реформирования государственных банков. // Экономический обзор, 2005 (04): 126-128.

6. Гао Цяньцянь, Фань Хун. Исследование макропруденциального надзора за банковской системой Китая. // Исследования и управление операциями, 2020, 29 (03): 158-168.

7. Ли Цюань, Цзинь Сюань. Изменения в банковской отрасли Китая: исследование практики и перспективы развития. // Социальные науки, 2020, 35 (06): 49-54.

8. Дин Ибин, Ван И. Структурные изменения в банковской отрасли Китая (1897-1927). // Шанхайское экономическое исследование, 2020 (03): 109-117.

9. Лу Минфэн, Чжоу Цзюнюй. Обзор 70-летнего следа развития банковской отрасли Китая, а также исследования и оценки ее будущих 
тенденций. // Журнал Университета Цзинань (издание по общественным наукам), 2019, 29 (04): $5-19+157+2$.

10. Фань Чжиган. Развитие банковской индустрии Китая за последние 40 лет реформ и открытости. // Линия фронта, 2019 (01): 25-28.

11. Чэнь Вэйдун, Чжан Синжун, Сюн Циюе, Юань Сяохуэй. Открытие банковской отрасли Китая внешнему миру: развитие, влияние и политика. // Исследование финансового надзора, 2018 (10): 1-17.

12. Хуан Жунчжун. Ускорение модернизации банковской отрасли Китая в новую эпоху посредством цифровой трансформации. // Финансовый мир, 2018 (10): 17-19.

13. Чэнь Бинцай. Достижения и опыт реформы и открытости банковской отрасли Китая. // Финансовое время, 2018-06-25 (009).

14. Чжао Жуй, Обзор литературы о развитии банковской индустрии Китая. // Западная кожа, 2017, 39 (24): 55-56. 